\title{
A prática da pesquisa documental em Psicologia
}

\author{
Denise Bacellar Nunes \\ Universidade de Brasília, Biblioteca Central, Brasília, DF, Brasil \\ prof.denisebacellar@gmail.com \\ Elmira Simeão \\ Universidade de Brasília, Faculdade de Ciência da Informação, Brasília, DF, Brasil \\ elmirasimeao@gmail.com \\ Ondina Pereira \\ Universidade Católica de Brasília, Brasília, DF, Brasil \\ ondinapena@gmail.com
}

DOI:DOI: https://doi.org/10.26512/rici.v13.n1.2020.29608

Recebido/Recibido/Received: 2020-01-02

Aceitado/Aceptado/Accepted: 2020-02-13

Resumo: A prática da pesquisa documental tem sido um desafio para diversas áreas do conhecimento, pois para executá-la é preciso observar além do documento e de seu conjunto organizado. A prática de uso da documentação depende de certas condições para sua apropriação enquanto objeto. Para possibilitar a aproximação entre a Psicologia e área de informação por meio da apropriação de registros descreve-se então a caracterização geral da produção científica que marca a construção epistemológica da produção da pós-graduação em Psicologia da Universidade Católica de Brasília.Com a organização da produção científica decorrentes da formação em nível mais avançado e a análise quantitativa e qualitativa de trabalhos (teses e dissertações), sua distribuição anual e orientadores em 16 anos de Programa, foi possível identificar algumas aproximações epistemológicas de cunho teórico-ontológico. Para essa pesquisa foram analisados 252 trabalhos produzidos por alunos do Programa da universidade. O trabalho se insere numa investigação mais ampla que propõe como desafio um planejamento mais assertivo na formação a partir de estratégias de uso da documentação e das competências em informação para sua disseminação e uso.Para melhor elucidar a questão,abordaremos o papel do documento na compreensão da realidade e sua inserção na formação e prática clínica do psicólogo. Ademais mostraremos como a documentação relaciona-se com a subjetividade humana e seu papel na arquitetura da informação. Dessa forma é possível dar maior visibilidade à documentação e seu papel na pesquisa integrada da Psicologia e Ciência da Informação, contribuindo com informações relevantes nessa aproximação.

Palavras-chave: Documentação. Psicologia. Diplomática. pesquisa.

The practice of documentary research in Psychology

Abstract: The practice of documentary research has been a challenge for several areas of knowledge, because to perform it is necessary to go beyond the document and its organized set. The practice of using the documentation depends on certain conditions for its appropriation as an object. To enable the approximation between Psychology and information area through the appropriation of records, the general characterization of scientific production that marks the epistemological construction of the production of graduate studies in Psychology of the Catholic University of Brasilia is described: The identification and organization of scientific production for the formation of the psychologist at the more advanced level and the quantitative and qualitative analysis of works (theses and dissertations), its annual distribution and its advisors in 16 years, where some epistemological approximations of a theoretical-ontological nature are identified. For this initial research, 252 studies produced by students of the Graduate Program in Psychology were analyzed. The work is part of a broader investigation that 
proposes as a challenge a more assertive planning in training based on strategies for the use of documentation and skills for its dissemination and use. To better elucidate the issue, we will address the role of the document in understanding reality and its insertion in the training and clinical practice of the psychologist. In other time we will show how documentation relates to human subjectivity and its role in information architecture. Thus, it is possible to give greater visibility to documentation and its role in integrated research of Psychology and Information Science, contributing relevant information in this approximation.

Keywords: Documentation. Psychology. Diplomatic. research.

\section{La práctica de la investigación documental en Psicología}

Resumen: La práctica de la investigación documental ha sido un reto para varias áreas del conocimiento, ya que para realizarla es necesario observar más allá del documento y su conjunto organizado. La práctica de utilizar la documentación depende de ciertas condiciones para su apropiación como objeto. Para permitir la aproximación entre Psicología y área de información a través de la apropiación de registros, se describe la caracterización general de la producción científica que marca la construcción epistemológica de la producción de estudios de posgrado en Psicología de la Universidad Católica de Brasilia. Con la organización de la producción científica resultante de la formación en el nivel más avanzado y el análisis cuantitativo y cualitativo de las obras (tesis y tesis), su distribución anual y asesores en 16 años del Programa, fue posible identificar algunas aproximaciones epistemológicas de naturaleza teórico-ontológica. Para esta investigación, se analizaron 252 estudios realizados por estudiantes del Programa Universitario. El trabajo forma parte de una investigación más amplia que propone como desafío una planificación más asertiva en la formación basada en estrategias para el uso de la documentación y las habilidades de información para su difusión y uso. Para dilucidar mejor el tema, abordaremos el papel del documento en la comprensión de la realidad y su inserción en la formación y práctica clínica del psicólogo. En otro tiempo mostraremos cómo la documentación se relaciona con la subjetividad humana y su papel en la arquitectura de la información. Así es posible dar mayor visibilidad a la documentación y su papel en la investigación integrada de Psicología y Ciencias de la Información, aportando información relevante en esta aproximación.

Palabras clave: Documentación. Psicología. Diplomática. Investigación.

\section{Introdução}

A pesquisa documental auxilia na problematização de práticas humanas e sociais, na desnaturalização das mesmas e na ruptura de suas cristalizações (LE GOFF, 2013).Sendo assim, inferimos que a memória humana coletiva em sua forma científica, pode ser elucidada pela pesquisa documental em duas perspectivas: como documento e também como monumento. Para melhor entendermos essa acepção, partimos do princípio de que o que sobrevive em um determinado acervo não é o conjunto de registros que existiu no passado, mas uma escolha efetuada pelas forças que operam no desenvolvimento temporal do mundo e da humanidade (LE GOFF, 2013).

Segundo Le Goff (2013, p. 535-553), os materiais da memória podem apresentar-se sob duas formas principais: os monumentos, herança do passado, e os documentos, fonte de informação determinada pela busca e escolha do pesquisador. Esses conceitos foram popularizados na Psicologia no século XX, nas obras $O$ Nascimento da Clínica (FOUCAULT, 2011), História da Loucura (FOUCAULT, 2014) e Arqueologia do Saber (FOUCAULT, 2012) de Michel Foucault. Mas convém realçar que tanto o conceito de monumento como o de 
documento, são conceitos muito antigos, e anteriores a Foucault. Na Psicologia esses conceitos interferem na pesquisa documental da área e convém explorá-los nessa investigação (numa abordagem conjugada com a perspectiva objetiva da Ciência da Informação).

A palavra latina monumentum remete para a raiz indo-europeia men, que exprime uma das funções essenciais do espírito (mens), a memória (memini). O verbo monere remete $a$ 'fazer recordar', de onde 'avisar', 'iluminar', 'instruir'. O monumentum é um sinal do passado. Atendendo às suas origens filológicas, o monumento é tudo aquilo que pode evocar o passado, perpetuar a recordação, por exemplo, os atos escritos (CUNHA, 2010; LE GOFF, 2013).

O monumento tem como característica principal o fato de ligar-se ao poder de perpetuação, voluntária ou involuntária das sociedades históricas, considerado um legado à memória coletiva e que tem a capacidade de reenviar a testemunhos (CUNHA, 2010). Convém lembrar que só uma parcela mínima são testemunhos escritos.

Já o termo latino documentum, derivado de docere- ensinar (mesmo radical de docente, ou seja, aquele que ensina fazendo uso da documentação científica) evoluiu para o significado de prova. Tome-se como exemplo a abordagem precisa e contundente amplamente usada no vocabulário legislativo e judiciário. Segundo Le Goff (2013), no século XVII se difunde, na linguagem jurídica francesa, a expressão titres et documents e o sentido moderno de testemunho data apenas do início do século XIX.

Documento é o livro, a revista, o jornal, é a peça de arquivo, a estampa, a fotografia, a medalha, a música, é também atualmente o filme, o disco e toda a parte documental que precede ou sucede a emissão radiofônica. Ao lado dos textos e imagens há objetos documentais por si mesmos (realia) (OTLET, 2008 , p. 6). (grifo nosso e tradução nossa)

A partir da definição acima, o documento se propõe a extrapolar a dimensão de suporte em direção à informação contida nos variados registros localizados em diferentes instituições e com objetivos de descrever a prova ou testemunhar uma descrição de fatos e atos. Dessa forma, os documentos abrem caminho para a formação da memória, dando sentido e rumo a acontecimentos. Independente dos formatos e suportes em que são registrados, detalha e informa sobre o presente para a memória futura. Esse entendimento se torna mais complexo pois aponta para a multiplicidade de suportes e cria os contornos de totalidade e universalidade propostos por Otlet(2008).

O documento que, para a escola positivista do fim do século XIX e do início do século $\mathrm{XX}$, era considerado o fundamento do fato histórico, ainda que resultante da escolha, de uma decisão do pesquisador, parece apresentar-se por si mesmo como prova histórica e afetado pela diversidade de possiblidades de sua recuperação e leitura. Observamos ao analisar essa concepção que a objetividade do documento parece opor-se à intencionalidade do 
monumento, afirmando-se também como um testemunho escrito ou melhor, registrado.

Mas foi no final do século XIX que o testemunho válido de documento e monumento se transformou. A leitura dos documentos não serviria para nada se fosse feita com ideias preconcebidas (CERTEAU, 2011; LE GOFF, 2013 ). Dessa forma, a habilidade do pesquisador passa a consistir em tirar dos documentos tudo o que eles contêm. $\mathrm{O}$ pesquisador na pesquisa documental é aquele que se mantém o mais próximo possível dos textos. Para Miranda e Simeão (2002) a definição de informação e particularmente a de "documento" estaria sujeita a reformulações e reconceitualizações pari passu com a evolução da própria pesquisa afetada pelas possibilidades do contexto em que é desenvolvida. Para os autores essa questão conceitual (sempre em voga na Ciência da Informação e nas intercessões com outros estudos) é complexa e discutir se deveria ou não ter uma concepção única parece não só impraticável, mas principalmente inócuo. Dessa forma para a Psicologia, buscando uma objetividade, também é válido afirmar que o mais realista é observar o documento como informação objetiva, e mesmo como realia, trata-se de um registro afetado por todas as possibilidades de seu contexto.

\begin{abstract}
A polissemia do conceito de "informação" parece ser uma decorrência natural da apropriação do termo por diferentes áreas do conhecimento e está ligada ao fenômeno conhecido como "definição consuetudinária" em que diferentes especialistas se expressam conforme o estado da arte dos conhecimentos sobre determinado fenômeno(MIRANDA E SIMEÃO, p. 2, 2002).
\end{abstract}

Em princípio, o documento era sobretudo um texto,textos são monumentos escritos que demandavam às línguas mortas os seus segredos (CERTEAU, 2011; LE GOFF, 2013), Com a descoberta da imprensa por Gutenberg e a revolução documental, o documento impresso adquiriu uma nova perspectiva: em lugar do fato que conduz ao acontecimento e de uma história linear, o documento passa a carregar em si uma memória progressiva. Na sociedade de massa ele passa a privilegiar a informação imediata, que leva à série e a uma história descontínua, passível de diferentes interpretações e acessos.

Com o advento do boom da documentação, a memória coletiva valoriza-se, institui-se em patrimônio científico cultural e também de "massa". O documento passa a representar uma nova concepção, até evoluir em seu armazenamento físico para o armazenamento digital nos bancos de dados e repositórios institucionais. Uma massa documental agora transformada em dígitos. Na transição de armazenamento da documentação, o documento passa a exigir do pesquisador uma nova erudição que deve responder simultaneamente às exigências do computador e à crítica da sua sempre crescente influência sobre a memória coletiva. Nasce daí a necessidade de adaptar a interação entre os humanos e os novos 
suportes de documentos e o desenvolvimento das Competências em Informação (Colnfo). Essas competências baseiam-se na atitude humana aprendida para acessar o mundo da documentação, percebendo o que a massa documental pode revelar (SIMEÃO; MIRANDA, 2006).

Conclui-se que a pesquisa documental auxilia na problematização de práticas humanas e sociais. Seguindo o raciocínio de Le Goff (2013) também ajuda na ruptura de suas cristalizações. A memória humana em sua forma científica (e coletiva), pode ser elucidada pela pesquisa documental em duas perspectivas: como documento e também como monumento, e o que fica como registro não é o aquilo que existiu no passado, "mas uma escolha efetuada pelas forças que operam no desenvolvimento temporal do mundo e da humanidade" (LE GOFF, 2013, p. 553). Uma breve revisão de literatura desse tema nas áreas da História, Diplomática, Ciência da Informação e Psicologia, pode ajudar a refletir sobre a pesquisa documental e o conceito ontológico de documento/monumento e sua contribuição ao campo de pesquisa da Psicologia.

\section{Revisão de literatura - 0 papel do documento na elucidação da realidade}

Para Foucault (2012), "os documentos ocupam um papel social e o que transforma o documento em monumento é a sua utilização pelo poder" (FOUCAULT, 2012, p. 13). Para esse autor, não existe um documento objetivo, inócuo, primário. A ilusão positivista a qual via no documento uma prova de boa-fé, desde que fosse autêntico, pode muito bem detectar-se ao nível dos dados mediante os quais a atual revolução documental tende a substituir os documentos.

A concepção do documento/monumento é, pois, independente da revolução documental e entre os seus objetivos está o de evitar que esta revolução necessária se transforme num derivativo e desvie o pesquisador do seu dever principal: a crítica do documento considerando a importância de sua arquitetura. $O$ documento não é qualquer coisa que fica por conta do passado, é um produto da sociedade que o fabricou segundo as relações de forças que aí expressavam a hegemonia. Só a análise do documento enquanto monumento permite à memória coletiva recuperá-lo e ao pesquisador usá-lo cientificamente, isto é, com pleno conhecimento de causa. A comunicação científica, por exemplo, se alimenta dessa combinação. Mesmo com uma visão cartesiana que coloca informação como documento objetivo e concretamente analisável em conteúdo e forma, como dados operacionais, ou como um objeto passível de ser avaliado fisicamente, Miranda e Simeão (2002) consideram, tal qual Foucault, que a apropriação social é capaz de transformar sua acepção e valor. 
Todo documento (no sentido de informação registrada) está exposto a diferentes abordagens, dependendo dos propósitos de busca, mas seria possível apontar duas direções complementares e interdependentes: a primeira voltada para o conteúdo enquanto tal e a segunda para a estrutura do próprio documento. As diversas áreas de pesquisa são conduzidas pelo conhecimento disciplinar consubstanciado nos registros, questionando-os e reformulando-os constantemente segundo a prática postulada pela Teoria do Conhecimento Objetivo (Popper) da cadeia produtiva das "conjecturas e refutações"(MIRANDA E SIMEÃO, p. 3, 2002)

Michel Foucault colocou claramente essa questão para a Psicologia em seus estudos arqueológicos. Antes de mais nada, declarou que os problemas da história podem se resumir numa só palavra: “o questionar do documento" (FOUCAULT2012, p. 13). E logo recorda: “O documento não é o feliz instrumento de uma história que seja, em si própria e com pleno direito, memória: a história é uma certa maneira de uma sociedade dar estatuto e elaboração a uma massa documental de que se não separa" (Idem). Partindo dessa premissa, entendemos que um documento é o resultado de várias forças entrecruzadas, sendo uma montagem que é o efeito de práticas concretas. "Dito de outra maneira, é preciso desviar os olhos dos objetos naturais para perceber uma certa prática, muito bem datada, que os objetivou sob um aspecto datado como ela" (VEYNE, 2008, p. 243).

Considerando a importância do documento-monumento para a pesquisa documental em Psicologia, situamos que a pesquisa documental nesse caso auxilia na problematização de práticas sociais, trata-se de um olhar questionador e crítico da atualidade "que produz um pensar interrogante e estabelecido no espanto, no estranhamento, em um exercício constante de demolição de evidências" (LEMOS \& CARDOSO JÚNIOR, 2009, p. 353).

Na relação com a Ciência da Informação, a prática de análise documental se ampara na vertente mais objetiva e pragmática, mas também leva em conta os aspectos históricos e sociais relevantes já que a $\mathrm{Cl}$ está voltada para compreender a natureza e uso social dos documentos por métodos quantitativos e qualitativos ${ }^{1}$.

Foucault (2008) e Deleuze (2016) propuseram a perspectiva teórico-prática de que para criticar as verdades e realidades dadas é preciso problematizar. Esses autores concordam que problematizar a documentação permite pensar,fazer e questionar uma escrita da história dessa realidade. Ademais os documentos são imprescindíveis para a construção de uma trama de intrigas e para forjar as ferramentas de desnaturalização das práticas estabelecidas. Tanto Foucaut (2008) como Deleuze (2016) acreditam que a história também nos cerca,

\footnotetext{
${ }^{1}$ Ler em MIRANDA, Antonio. A Ciência da Informação e teoria do Conhecimento Objetivo: um relacionamento necessário. In: Campo da Ciência da Informação: gênese, conexões e especificidades. João Pessoa: Editora da UFPb, 2002.
} 
delineia-nos como modos de viver e de ser, de pensar e de agir; não diz o que somos, mas aquilo em que estamos em vias de nos tornar (DELEUZE,2016).

\subsection{Arquitetura da informação e significado na análise da documentação em Psicologia}

Miranda e Simeão (2002) apresentam os elementos constitutivos do documento em seu processo criativo. Os autores ao argumentarem a criação de sentidos na leitura e percepção da documentação, ressaltam os aspectos objetivos do objeto e sua composição compreendida em: "Tipo - Conteúdo - Formato e Suporte". Segundo os autores a estrutura do documento é vista como uma célula que organicamente afeta e é afetada na sua exposição e uso e responde aos interesses da argumentação de autores e instituições:

(...) Pode ser vista de forma orgânica ou sistêmica, quando a variável humana e o conteúdo interagem com a tecnologia mudando padrões e convenções institucionais. Observando as publicações, sua história e evolução, considera-se que a massa documental (o Mundo 3 de Popper), é reconhecida como a expressão de pensamentos e experiências científicos, literários e artísticos, é codificada mediante uma arquitetura em várias dimensões.(Miranda; Simeão, 2002)

Quadro 1 - Elementos constitutivos do documento.

\begin{tabular}{|l|l|}
\hline Suporte & $\begin{array}{l}\text { base física que reúne as ideias construídas em um } \\
\text { determinado formato. }\end{array}$ \\
\hline Formato & $\begin{array}{l}\text { desenho ou arquitetura que determina a leitura } \\
\text { de um texto e sua sequência. }\end{array}$ \\
\hline Conteúdo & $\begin{array}{l}\text { ideia (original ou não) que precisa ser disseminada } \\
\text { para gerar novas ideias. }\end{array}$ \\
\hline Tipificação & $\begin{array}{l}\text { formas de classificar as publicações que } \\
\text { disseminam o conhecimento. }\end{array}$ \\
\hline
\end{tabular}

Fonte: Miranda e Simeão, 2002.

\subsection{A documentação em arquivos e sua relação com a Psicologia}

A prática profissional do psicólogo gera naturalmente documentos de arquivo. Ao analisarmos a produção dos arquivos como suportes de guarda de documentos selecionados e conservados, podemos ao mesmo tempo também interrogá-los sobre a constituição dos mesmos, sobre os discursos que trazem e sobre as relações de poder que ensejam, sobre as imagens que são divulgadas, as cores e os carimbos que estão presentes nos documentos, etc., contribuindo para a formulação de inúmeras indagações. (CASTRO,2008; BACELLAR, 2011).

Segundo Gomes (1976, p. 5), o documento de arquivo é considerado “[...] peça escrita ou impressa que oferece prova ou informação sobre um assunto ou matéria qualquer". Inferimos através dessa definição que o documento se vincula a materiais físicos, que de alguma forma são registrados. Esses documentos são guardados e conservados em arquivos, 
que, por sua vez, consistem em um local onde se armazenam conjuntos de documentos com a finalidade de tornar acessível o uso das informações contidas nos mesmos. Não obstante, quando analisamos os escritos de (PAES, 2010, p. 26), o documento consiste no "[...] registro de uma informação independente da natureza do suporte que a contém". A autora acrescenta que a distinção entre o conceito de documento e de documento de arquivo reside na diferença de sua origem e de sua coleta, a saber: "1) Aquele que, produzido e/ou recebido por uma instituição pública ou privada, no exercício de suas atividades, constitua elemento de prova ou informação; 2) Aquele produzido e/ou recebido por pessoa física no decurso de sua existência".

$\mathrm{O}$ arquivo pode ser de documento sonoro, gravado e visa recolher, pelas entrevistas, observações e diários de campo, rastros, redes de intrigas, relações de pertencimentos e testemunhos (MALATIAN, 2009). A partir desse fragmento concluímos que a noção de documento é ampla e pode ser composta como vestígio das práticas, dos nossos fazeres no tempo e no espaço (ALBERTI, 2010). Dessa forma a história da vida privada, da alimentação, da civilização, da sexualidade, da família, da infância, de uma política pública, dos intelectuais, dos costumes, da cultura, das religiões, da arte, entre outras, pode ser objeto de interesse da documentação em Psicologia (FERREIRA,2009), passando, a partir da experiência vivida, ser registrada em forma de arquivo.

Algumas tipologias documentais como cartas, diários íntimos, receitas, currículos, álbuns de família, pastas com contas pagas e certidões de batismo e de registro civil, entre outros, podem ser fontes históricas que interessam à problematização e à dimensão psicológica, na construção de subjetividades relacionadas com o tempo, o espaço, a cultura e a sociedade de uma determinada época (MALATIAN, 2009). Esses documentos podem compor o acervo de arquivos.

Segundo Rousseau os arquivos também são instituições públicas ou privadas, que têm como principais funções ou processos a: criação, avaliação, aquisição, classificação, descrição, comunicação e conservação dos documentos gerados em decorrência do exercício das atividades funcionais ou privadas que se estabelecem primordialmente pelas vias jurídicoadministrativas (ROUSSEAU; COUTURE, 1998). Além dessas funções técnicas, desdobram-se dos documentos outros entendimentos essenciais para o funcionamento dos arquivos, como os princípios da proveniência ou do respeito aos fundos, da territorialidade, do respeito à ordem natural, da pertinência ou princípio temático, e o princípio da reversibilidade (ARQUIVO NACIONAL, 2005). Além destes princípios, os documentos de arquivo possuem certas características que Ihes são peculiares tais como a unicidade, organicidade, indivisibilidade, 
integridade, autenticidade e heterogeneidade de seu conteúdo (BELLOTTO, 2002; MARTíNPOZUELO CAMPILLOS, 1996).

Se por um lado a prática do psicólogo gera documentos de arquivos, a formação do psicólogo é baseada em documentos bibliográficos, periódicos e outros, que estão organizados em bibliotecas. O conceito de documento para a Biblioteconomia guardaria contornos muito próximos da definição oriunda da própria documentação, pois os documentos não seriam apenas os livros, mas todas as formas documentais. Na análise documental seja ela de perspectiva arquivista ou bibliográfica, há sempre traços marcantes que expressam aspectos definidores de uma área ou temática.

Quadro 2 - Noção de documento e diferenciação do documento de arquivo e de documento de biblioteca.

\begin{tabular}{|l|l|l|}
\hline \multicolumn{1}{|c|}{ Método } & \multicolumn{1}{c|}{ Biblioteconomia } & \multicolumn{1}{c|}{ Arquivologia } \\
\hline Problema & Análise da literatura científica & $\begin{array}{l}\text { Comprovação da } \\
\text { origem }\end{array}$ \\
\hline Método & Ênfase no conteúdo/assunto & $\begin{array}{l}\text { Ênfase na } \\
\text { autenticidade/função }\end{array}$ \\
\hline Desenvolvimento & Técnico-científico & $\begin{array}{l}\text { Jurídico- } \\
\text { administrativo }\end{array}$ \\
\hline
\end{tabular}

Fonte: Bacellar (2011).

O quadro 2 constitui uma representação, entre outras possíveis, das leituras e do conceito de documento, de arquivo e de bibliotecas que, de modo transversal e salvaguardadas as especificidades das áreas. Nestes termos o documento conduz a um contorno que não se prende a uma tentativa de mostrar forçosamente os pontos de convergência entre a Arquivologia e a Biblioteconomia. Notamos que a proposta evidencia alguns aspectos do conceito de documento referente àquelas áreas do conhecimento que, de alguma maneira, compartilham deste conceito. Portanto, novas abordagens como a de Miranda e Simeão e a de Bernd Frohmann (2008), que define o documento como a "materialidade da informação", têm conduzido o entendimento de que a informação está igualmente presente nessas áreas e na Ciência da Informação, área do conhecimento que assume desde suas primeiras conceituações a informação como seu objeto de estudo (ARAÚJO, 2011). Com a visão objetiva proporcionada pela Arquivologia ou pela Biblioteconomia, pode-se promover ainda mais a aproximação proposta pela pesquisa. Convém realçar que a problematização, o questionamento e a crítica aos documentos devem estar inseridos em um contexto real, para que as proposições acerca deles possam ter efeitos. Em Psicologia, os contextos de uso dos documentos podem variar desde a formação 
até a atividade do psicólogo na clínica. Há portanto aspectos objetivos e subjetivos a considerar.

Segundo Miranda e Simeão (2002), na prática, há expectativas maiores ou menores e contextos a considerar segundo os tipos de documentos, objeto de instâncias reguladoras que vão das normalizações até aos mecanismos de editoração, acesso e uso: "O tipo de documento ou fonte também qualifica ou justifica o seu uso nas situações do processo produtivo da indústria da informação, criando veículos próprios para armazenagem e difusão (...)" (MIRANDA E SIMEÃO, p. 5, 2002).Acrescenta-se a essa visão aspectos de uso e de aplicação em determinadas circunstâncias, como é o caso da formação nas escolas de psicologia e da atuação e produção documental de seus profissionais no "mercado". Com a prática da análise documental pode-se até inferir situações de crises e impactos psicológicos ou verificar o perfil de pessoas em situações de vulnerabilidade social.

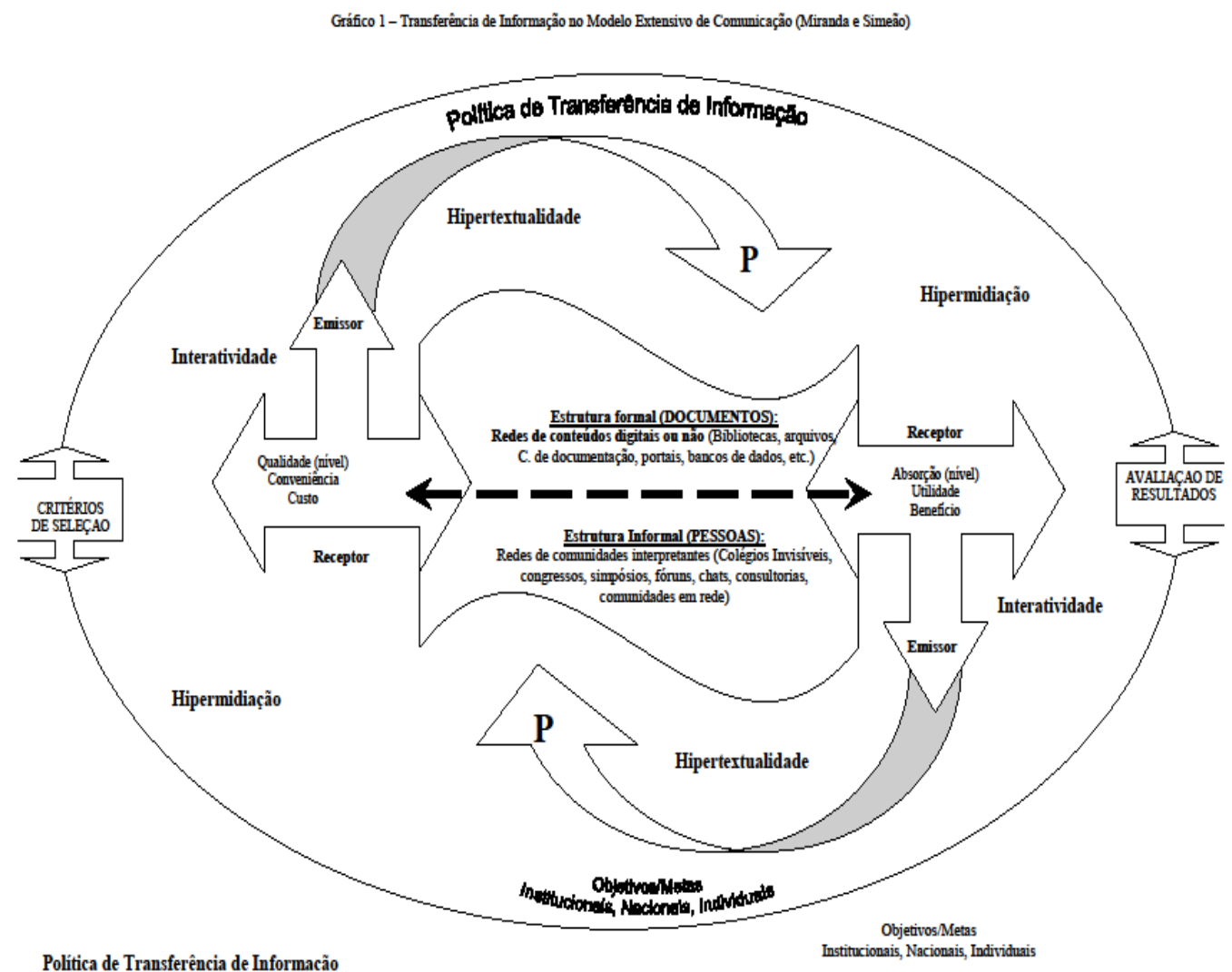

Fonte: Miranda e Simeão 2012

No gráfico 1 de Miranda e Simeão, que expressa as variáveis de análise entre documentos e pessoas para uma política de informação, pode-se verificar a multiplicidade de combinações possíveis numa pesquisa de análise documental. Se observa a partir das 
características do documento os elementos que ajudam a entender a própria subjetividade dos registros, nesse caso numa proposta de análise em instituição vinculada a formação em psicologia. Em um estudo de caso bem pontual ao avaliar a produção científica da área podese inferir traços da trajetória de uma instituição em registros de produção documental e a política de informação adotada. Mesmo quando considerada estrutura documental objetiva (material), é imprescindível observar a natureza histórica e a prática social das instituições e profissões em questão. No uso e manipulação da massa documental aspectos externos ao documento são fundamentais, como a disponibilidade e a tecnologia de acesso aos documentos. Qualquer que seja a análise será sempre própria de um conjunto de usuários e seu contexto. Com essa perspectiva os autores defendem os componentes de uma política de informação que depende e funciona a partir de estruturas formais e informais compostas de pessoas e de documentos. A tecnologia e seus impactos afetam o ciclo que considera outros aspectos de oferta e demanda de informação (MIRANDA; SIMEÃO, 2002).

\subsection{A Documentação na vivência do psicólogo}

Uma consideração subjetiva da documentação e de seu uso em Psicologia diz respeito à formação do psicólogo nas faculdades de Psicologia e ao cotidiano de sua prática na clínica. Essa é uma das formas de tratar a massa documental com técnicas objetivas advindas da $\mathrm{Cl}$ e revelar aspectos objetivos e subjetivos da Psicologia. Através da análise dos documentos envolvidos na formação dos egressos em Psicologia, por exemplo, podemos elucidar questões subjetivas envolvidas e subjetivadas no discurso da formação do psicólogo.

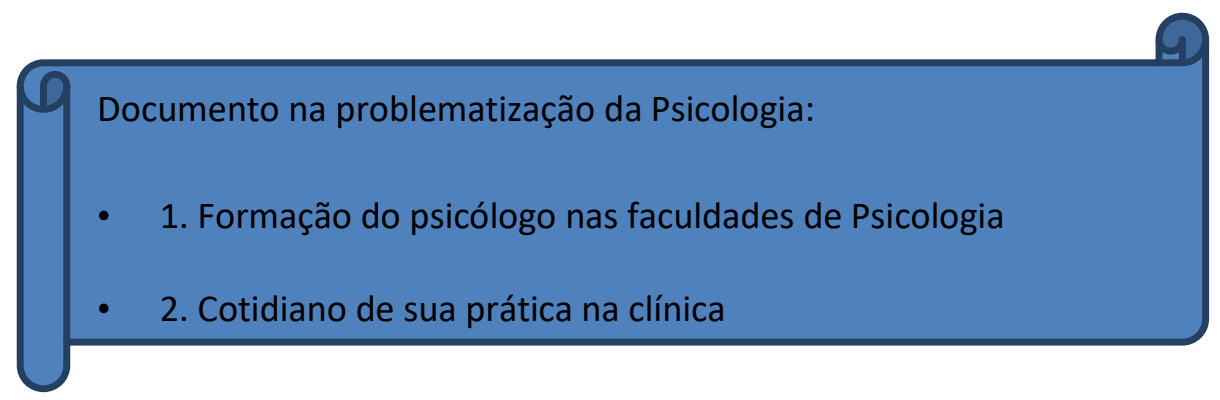

$\mathrm{Na}$ análise documental da formação do psicólogo pode-se observar o arcabouço teórico do curso, sistematizado em sua bibliografia básica e nos repositórios institucionais da produção acadêmica, onde são depositados os trabalhos de conclusão de curso na área de Psicologia(LEMOS, 2012; LEMOS et al., 2015). Dessa forma, e com técnicas objetivas aporta-se importantes aspectos subjetivos da área e seu contexto, conforme destacam Miranda e Simeão: 
Por que é importante identificar a tipologia do documento na presente análise? Certamente a resposta está na percepção de que o tipo de documento predispõe a autoria, condicionando o processo de registro do documento e, consequentemente, os demais elementos do ciclo informacional. Como registro público, o documento sacramenta uma prédisposição consentânea com um objetivo a ser atingido e um uso predeterminado que precisa ser identificado pelo público. (MIRANDA; SIMEÃO, 2002, p. 5)

Já no cotidiano do trabalho dos psicólogos, também há uma expressiva produção de documentos: relatórios de atendimento, projetos, dossiês, pareceres, laudos, e há também a guarda desses em arquivos, uns sigilosos e outros não. Os psicólogos também recebem documentos de outros profissionais para exercer suas práticas e tomar decisões: queixas, denúncias, laudos médicos, pedidos do Poder Judiciário, encomendas das escolas, diários de família, pedidos de aplicação de testes e avaliações, encaminhamentos de clientes, solicitações de laudos, queixas escolares, entre outros.

Parte do trabalho do próprio psicólogo é também analisar os documentos e os seus efeitos na vida das pessoas, pesquisar e ouvir as histórias de vida, arquivar essas histórias para, em algum momento, produzi-las como documentos. Assim, tanto a narrativa oral quanto a escrita das histórias são material para se pensar a produção de subjetividades expressas em forma de documentação (FRANÇOIS, 2006). O Conselho Federal de Psicologia (CFP), através dos seus conselhos regionais, normaliza a prática do registro da documentação criada pelo psicólogo, como podemos observar no fragmento:

Toda/o psicóloga/o, na prestação dos seus serviços, encontra-se obrigada/o, além do registro dos conteúdos obtidos, a informar os resultados desses serviços a quem de direito, fornecendo, sempre que solicitado, os documentos pertinentes ao bom termo do trabalho, conforme prevê o Código de Ética do/a Psicólogo/a no artigo $1^{\circ}$. (CONSELHO FEDERAL DE PSICOLOGIA, 2003)

Os documentos orais e escritos se tornaram também operadores de escuta psicológica e da produção da própria história da Psicologia como saber, poder e subjetivação. 0 conhecimento da documentação pode contribuir tanto com a prática profissional de psicólogos quanto com o campo de pesquisas dos fazeres e saberes do interesse da Psicologia. Como exemplo, destacamos a resolução do CFP (CONSELHO FEDERAL DE PSICOLOGIA, 2003), sobre a normalização de documentos psicológicos, que deve ser seguida no exercício da função de psicólogo:

O Conselho, através da Resolução do CFP n 07/2003, publicou o Manual de Elaboração de Documentos Psicológicos com orientações e modelos estabelecidos para a emissão dos seguintes documentos: Declaração, Atestado Psicológico, Relatório ou Laudo Psicológico e Parecer Psicológico. 0 Parecer e Declaração não são documentos provenientes de avaliação 
psicológica. Toda e qualquer comunicação por escrito deverá seguir as diretrizes descritas neste manual (CONSELHO FEDERAL DE PSICOLOGIA, 2003).

A aproximação da documentação $(\mathrm{Cl})$ com a Psicologia se dá pela preocupação das duas áreas com as relações e as diferenças entre a vida privada e a pública, pelo cotidiano e suas intercessões diversas entre subjetividade, cultura e sociedade fora de um campo de entidades fixas e universais. Sendo assim, a relação possível entre a documentação e a Psicologia permite inflexões mútuas (FRANÇOIS,2006). Há resoluções que ilustram essa proposição aplicada à prática do psicólogo e a normalização de posturas que orientam a escrita da documentação produzida pelo psicólogo.

Concluímos assim que a prática de uso da documentação depende de certas condições para sua apropriação enquanto objeto.

\section{Utilizando a documentação na caracterização geral da produção do PPGPSI da UCB}

Para possibilitar a aproximação entre a Psicologia e área de informação por meio da apropriação de registros descreve-se então a caracterização geral da produção científica que marca a construção epistemológica da produção da pós-graduação em Psicologia da Universidade Católica de Brasília - UCB: A identificação e organização da produção científica do curso para a formação em Psicologia em nível mais avançado e a análise quantitativa e qualitativa de trabalhos (teses e dissertações), sua distribuição anual e seus orientadores em 16 anos identificam algumas aproximações epistemológicas de cunho teórico-ontológico. Para essa pesquisa foram analisados 252 trabalhos produzidos por alunos do Programa de Pósgraduação em Psicologia da UCB. O trabalho se insere numa investigação mais ampla que propõe como desafio um planejamento mais assertivo na formação a partir de estratégias de uso da documentação e das competências para sua disseminação e uso.

Até dezembro de 2016 o Programa de pós-graduação em Psicologia da UCB produziu 253, trabalhos entre teses e dissertações, dos quais 248 correspondem a dissertações de mestrado e 4 teses de doutorado, conforme o gráfico 1. 
Gráfico 1: Pesquisas por nível e quantidade, visualização em fração

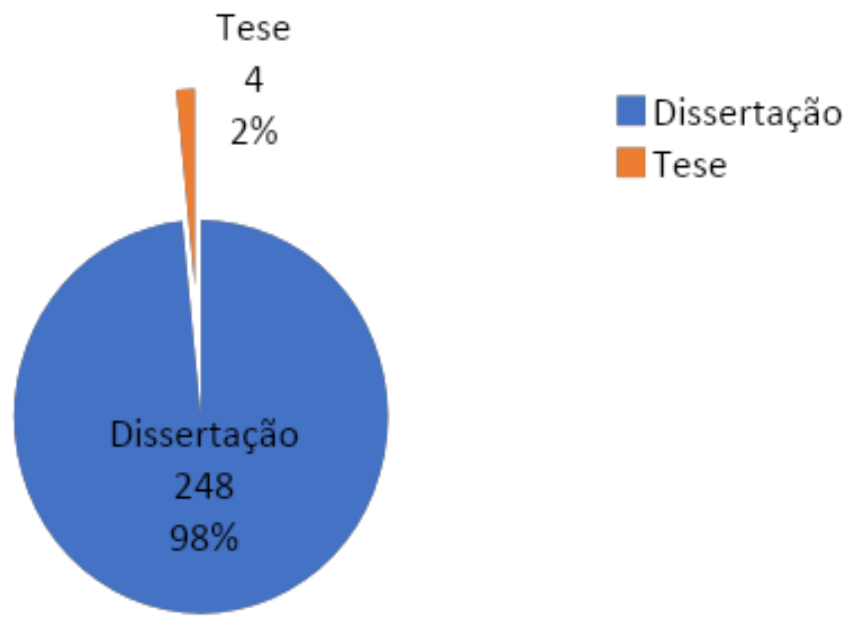

O gráfico 1 demonstra uma desproporção entre a quantidade de dissertações e teses analisadas no período de 2001-2016. Isso se deve ao fato de as primeiras teses aparecerem na produção, somente a partir de 2014, pois o doutorado foi a provado em 2011 no programa. Uma pista da aproximação de perspectivas e análise epistemológica diz respeito ao papel do orientador na produção do programa da UCB. Observamos que a formação acadêmica do orientador, a linha de pesquisa na qual milita, o grupo de pesquisa na qual está inserido, assim como seus pares de pesquisa e a distribuição de orientadores por orientação, ajudaram a influenciar os trabalhos produzidos ao longo dos anos. Observarmos que tanto a quantidade de trabalhos orientados, sua distribuição ao longo dos anos e a permanência ou a ausência do docente no programa, ajudaram a remodelar a construção da produção e consequentemente sua aproximação de tendências epistemológicas, influenciando a produção na sua sustentação sua teórica (gnóstica) e no seu sentido (ontológica).

Como o objetivo da pesquisa é descrever e analisar perspectivas epistemológicas observamos a distribuição das orientações da produção por orientador, para percebermos a sua organização e tendências epistemológicas. Outra questão importante diz respeito a parcerias disciplinares que foram requeridas na coorientação, um importante dado sobre a produção e principalmente na intersecção e aproximação de áreas disciplinares com a Psicologia. As aproximações e o afastamentos de trabalhos orientados pode oportunizar um importante veículo de descrição e análise das perspectivas epistemológicas. No gráfico começamos a descrever e analisar essa nuança e sua distribuição. 
Gráfico 2 - Quantidade de orientações por orientador

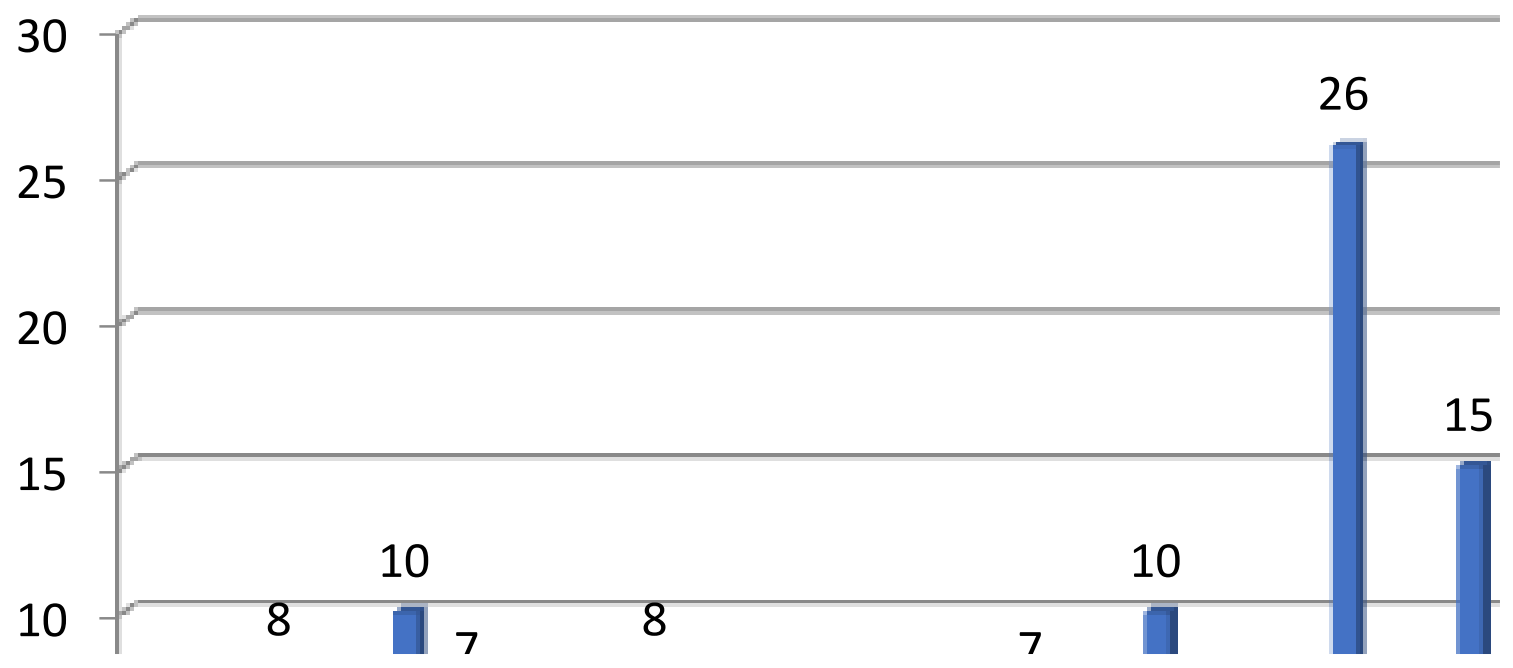

O gráfico 2 demonstra a distribuição desequilibrada na quantidade de orientações por orientador. Observamos que a média de orientandos por orientador prevaleceu abaixo de 10 orientações por orientador. Quando submetemos os mesmos dados da produção a uma análise de dispersão, observamos que dos 30 professores credenciados a orientação no programa, apenas 9 professores orientaram 70\% dos trabalhos, ao longo de 16 anos. Portanto, o restante dos 21 professores credenciados orientou os $20 \%$ restantes. Portanto a descrição e análise demonstram um desequilíbrio epistemológico, já que cada docente sustenta um determinado espectro disciplinar, uma linha de pesquisa e um conjunto de saberes distintos

Se considerarmos os professores e suas áreas principais de orientação que sustentaram teoricamente o programa, nos aproximamos as áreas distintas: a área das Ciências Sociais e o Desenvolvimento Humano e Psicanálise. Mas consideramos também, os trabalhos expressivos da área de família, sustentada pela Teoria Sistêmica, se aproximando dos fundamentos da Biologia, Teoria geral dos Sistemas, Cibernética, Teoria da Complexidade e do Holismo. Os trabalhos expressivos desses professores aproximaram inicialmente os orientadores e os trabalhos do programa a duas grandes áreas matrizes defendidas por Figueiredo (1999): uma mais reflexiva e outra mais científica da Psicologia, conforme defendido por Japiassú (1995).

Destacamos também os trabalhos que se aproximaram da área da teoria Sistêmica, criminologia, drogadição; os que se aproximaram da Fenomenologia e religiosidade e os trabalhos do que se aproximaram das áreas das Ciências Sociais: Representação Social, violência e juventude e gerontologia.A soma de todos os outros trabalhos se aproximou de áreas também representativas do programa: a Psicologia do desenvolvimento, Psicologia do trabalho e clínica do trabalho, da Psicologia escolar e da Psicanálise. 
Um outro achado demonstrado nesse gráfico foi que cerca de $25 \%$ de professores tiveram uma permanência curta no programa. Esse fato causou certa rotatividade nas áreas de pesquisa e nas linhas de pesquisa, que pode ter ocasionado mudanças epistemológicas na produção.

A análise do título do trabalho, das palavras-chaves, do problema e dos resultados esperados contribuíram para identificarmos algumas aproximações epistemológicas. Esses indicadores continham elementos como: traços metodológicos, técnicas, teorias, além de aspectos gnósticos e ontológicos e a tendência epistemológica dos estudos do PPGPSI. O que podemos perceber na análise desse acervo de teses e dissertações é que informações como o título do trabalho, palavras-chaves, descrição do problema e dos resultados demonstram indícios epistemológicos. A objetividade nos títulos, o uso de palavras-chaves advindos de vocabulários controlados como MESH e DESC (usados na área da saúde inclusive Psicologia) proporcionam uma clareza maior na redação do problema de pesquisa e resultados o que simplificaria a coleta facilitando a análise documental.

\section{Os sujeitos e objetos da pesquisa documental em psicologia}

O sujeito mais estudado no período analisado foi o próprio sujeito que frequentou a clínica de psicologia. O fato dele ter frequentado a clínica, juntamente com seus dilemas clínicos, foram objetos de pesquisa presentes com frequência nas pesquisas do PPGPSI/UCB . Verificamos que outros sujeitos também se destacaram ao longo da produção. Esses sujeitos estavam de certa forma ligados ao seu papel social:aluno, criança, adolescente, mulher, professor, o trabalhador, a família, o casal. Esses foram os grupos mais estudados, conforme demonstrado no gráfico 3.

Gráfico 3- Sujeitos/objetos de pesquisa

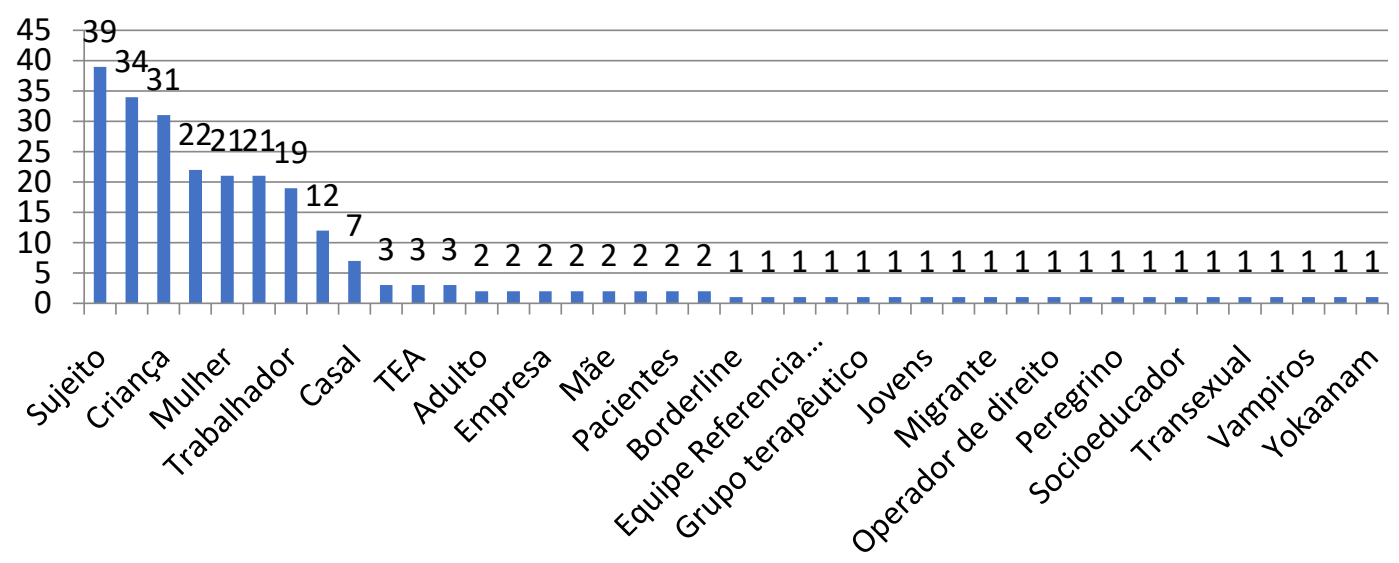


Outros estudos dedicaram-se a outros sujeitos representados pelo seu papel na sociedade, mas não foram tão substantivos quanto o grupo que obtiveram mais estudos.

\subsection{Variáveis estudadas no PPGPSI}

Cerca de 162 variáveis foram estudadas com sujeitos/objetos que orientaram a aproximação epistemológica dos estudos e teorias/ linhas teóricas. Elas constam na figura 1.

Figura 1Nuvem de TAG

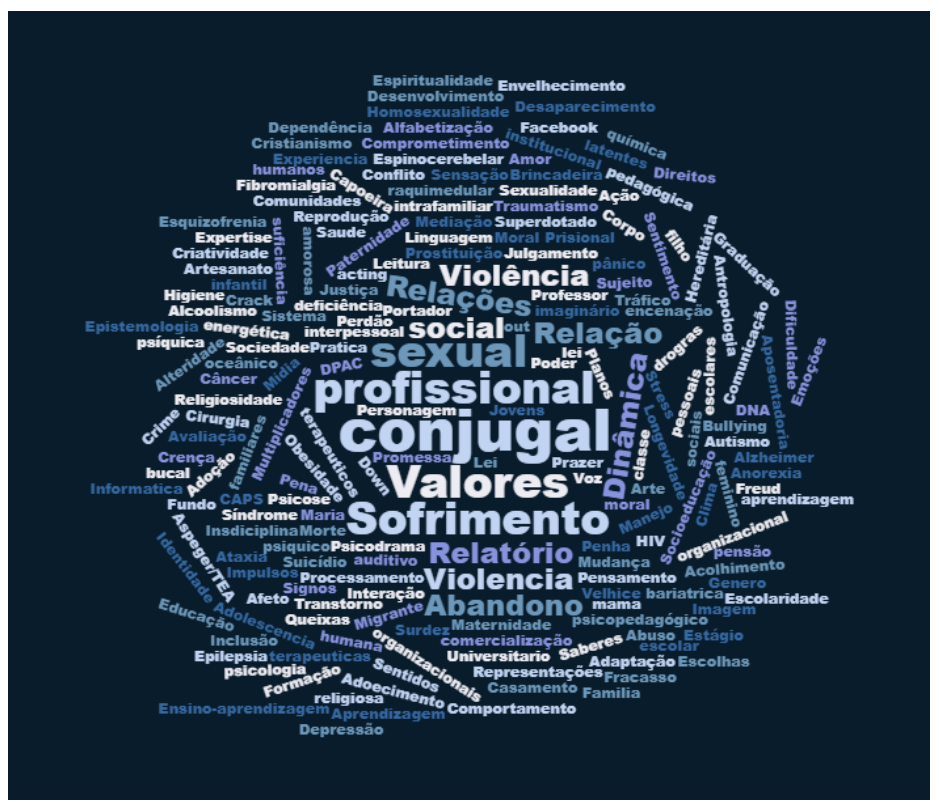

Fonte: as autoras.

A figura 1, nuvem de Tags, reúne todas as variáveis citadas nos trabalhos do PPGPSI. Nesse gráfico observamos a prevalência de algumas palavras que destacam-se do todo da pesquisa do PPGPSI: conjugal, profissional, valores, sofrimento, relações e violência. A nuvem 1 capta as palavras exatamente conforme a descrição do título das pesquisas. Observe como essas variáveis se articulam e confirmam sua aproximação e seu envolvimento ao contexto da "Clínica Psicológica”.

\section{2 Áreas de estudo que prevalecem no PPGPSI}

As áreas basilares da Psicologia estudada no PPGPSI dizem respeito a preferências teóricas e metodológicas contempladas ao longo dos 16 anos analisados. Observamos que os grandes grupos revelam pesquisas na área Sistêmica, Desenvolvimento, Escolar, Clínica, Trabalho, Psicanálise, Social e Fenomenologia. Outras áreas de estudo também aparecem em 
menor proporção. Destacamos aqui uma grande diversidade de áreas basilares que somadas equivaleriam até mesmo os grandes índices ou seja quase $1 / 4$ da produção é diversa :

Gráfico 4: Áreas basilares da Psicologia no PPGPSI

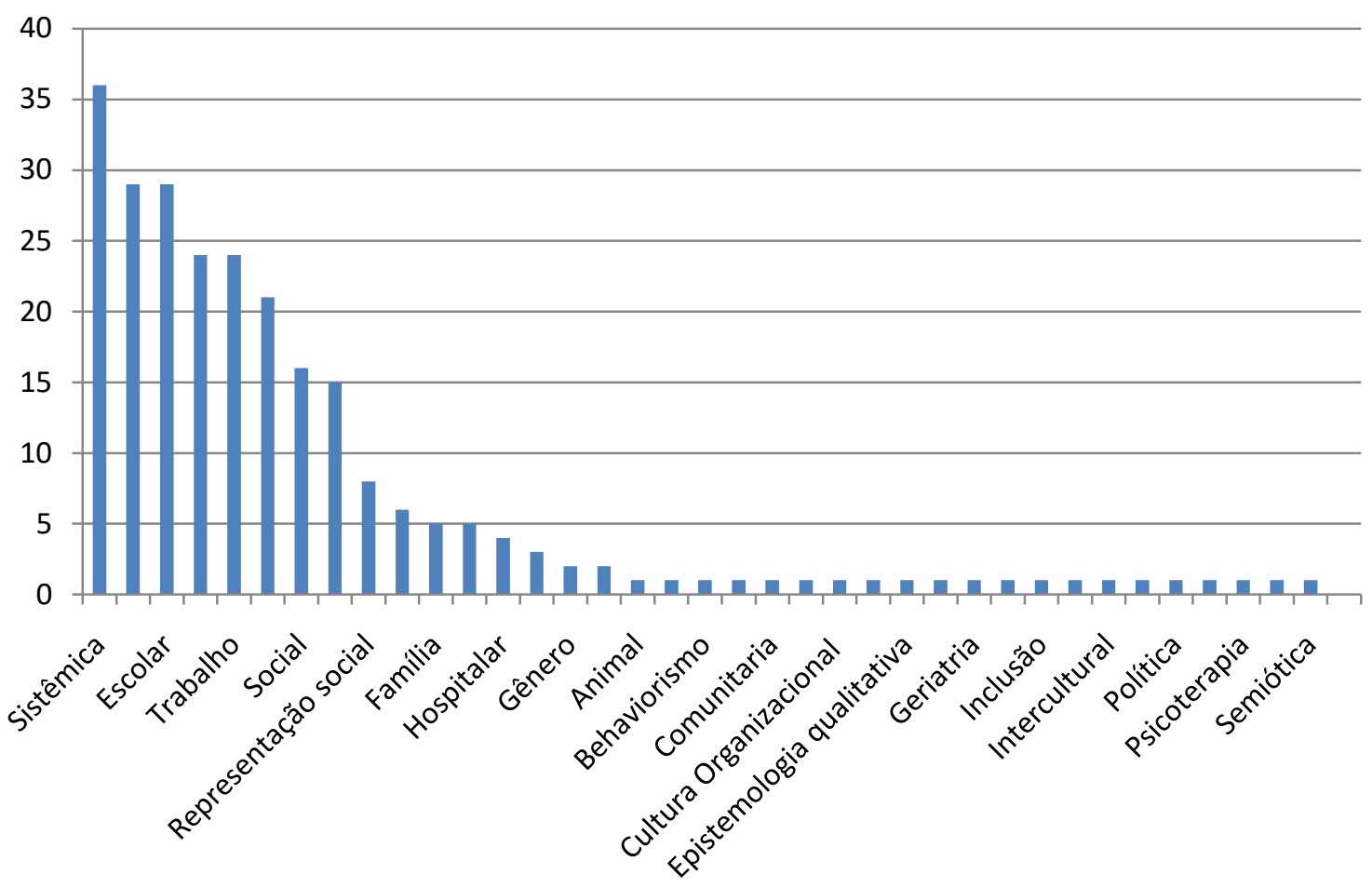

\section{Considerações finais}

Esse artigo teve como objetivo definir o documento/monumento e relatar a importância da pesquisa documental na pesquisa em Psicologia. Assinalamos a importância do documento como veículo de leitura da realidade, resgatando a importância do conhecimento da documentação na vivência do psicólogo de sua formação. Ademais também caracterizamos o documento como suporte de subjetividade e por fim, contribuímos com noções de arquitetura da informação para a significação (ontologia) da documentação em Psicologia, aproximando pesquisadores que abordam documentação, Ciência da Informação e a Psicologia. São inegáveis as contribuições da pesquisa documental na convergência das várias áreas de conhecimento e saberes. A descrição e a análise de documentos em seus diferentes suportes e arquiteturas, constituídos de acontecimentos que deixaram restos e marcas, vestígios no tempo e no espaço, contribuem para a verificação dos discursos, das verdades, revelando-os.

Salientamos que o documento, dependendo da situação, pode ter força de prova de verdade, assim como o poder de sinalizar pistas de que algo ocorreu no passado. Em ambos os 
casos, a ação humana é assim revelada por meio do tratamento das fontes documentais analisadas pelo pesquisador. Dessa forma, entendemos que aproximar os saberes da Psicologia com os saberes da Documentação, em sua concepção de documento/monumento, como fonte de análise de subjetividades e dimensões, é relevante na análise históricodocumental do campo epistemológico da Psicologia.

\section{Referências}

ALBERTI,V. Fontes orais: Histórias dentro da História. In: PINSKY,C. B. (Org.) Fontes históricas. São Paulo: Contexto, 2010, p. 155-201.

ARAÚJO, Carlos Alberto Ávila.Ciência da informação, biblioteconomia, arquivologia e museologia: relações institucionais e teóricas. Encontros Bibli, Florianópolis, v. 16, n. 31, p. 110- 130, 2011.

ARQUIVO NACIONAL (Brasil).Dicionário brasileiro de terminologia arquivística. Rio de Janeiro: Arquivo Nacional. 2005.

BACELLAR, C. Fontes documentais: uso e mau uso dos arquivos. In: PINSKY,C. B. (Org.). Fontes históricas. São Paulo: Contexto, 2010.p. 23-81.

BARRETO, Aldo. Uma quase história da ciência da informação. DataGramaZero, v.9. n. 2, 2008.

BELLOTTO, Heloisa Liberalli. Arquivos permanentes: tratamento documental. Rio de Janeiro: FGV, 2006. Cap. 2, p. 35-43.

CASTRO, C. Pesquisando em arquivos. Rio de Janeiro: Zahar, 2008.

CERTEAU, M. A escrita da História. Rio de Janeiro: Forense, 2011.

CUNHA, Antônio Geraldo da. Dicionário etimológico da Língua Portuguesa. São Paulo: Lexikon, 2010.

CONSELHO FEDERAL DE PSICOLOGIA.Resolução CFP N. 007/2003. Manual de Elaboração de Documentos Decorrentes de Avaliações Psicológicas. Brasília:2003.Disponível em:<http://www.crpsp.org.br/portal/orientacao/resolucoes cfp/fr cfp 007-

03 Manual Elabor Doc.aspx>Acessado em : 17 de julho de 2019.

CONSELHO REGIONAL DE PSICOLOGIA, 3a. Região.Posicionamento do CRP-03 acerca da produção de relatórios psicológicos em casos de alteração/adequação de nome no registro civil das travestis e das/os transexuais. Salvador: CRP3,2015. Nota Técnica Disponível em:<https://www.crp03.org.br/wp-content/uploads/2015/09/nota-t\%C3\%A9cnica.pdf>

Acessado em: 17 de julho de 2019.

DELEUZE, G. Conversações.Rio de Janeiro: Editora 34, 2016.

FERREIRA, A. C. Literatura: a fonte fecunda. In: PINSKY, C. B.; LUCA,T. R. (Org.).O historiador e suas fontes.São Paulo: Contexto, 2009. p. 61-92. 
FRANÇOIS, E. A fecundidade da história oral. In: AMADOJ.: FERREIRA ,M. M. (Org.). Usos \& abusos da história oral. 8. ed. Rio de Janeiro: FGV, 2006. p. 3-14.

FROHMANN, Bernd. O Caráter Social, Material e Público da Informação. In: FUJITA, M. S.L.; MARTELETO, R.M.; LARA, M.L.G. de. A dimensão epistemológica da Ciência da Informação e suas interfaces técnicas, políticas e institucionais nos processos de produção, acesso e disseminação da informação. São Paulo: Cultura Acadêmica Ed.; Marília: Fundepe, 2008. p. 1734.

GOMES, F. Araújo. Arquivo e documentação. Rio de Janeiro: Interciência, 1976.

FIGUEIREDO, L. Matrizes do pensamento psicológico. 20. ed. Petrópolis: Vozes, 2014.

FOUCAULT, Michel. O nascimento da clínica. São Paulo: Forense Universitária, 2011.

FOUCAULT, Michel . A história da Loucura. São Paulo: Perspectiva, 2014.

FOUCAULT, Michel. Arqueologia do saber. São Paulo, Forense Universitária, 2012.

JAPIASSU, H. Introdução a epistemologia da Psicologia. Rio de Janeiro: Imago, 1995.

LE GOFF, Jacques. História e Memória. In: Documento/monumento. 7. ed. Campinas, SP: Editora UNICAMP, 2013. p. 535-553.

LEMOS, F. C. S.; CARDOSO JR, H. R. A Genealogia em Foucault: Uma Trajetória. Psicologia e Sociedade, v. 21. n. 3,p. 353-357, 2009.

LEMOS, F. C. S;CARDOSOJR, H. R. Problematizar. In: FONSECA,T. G.; NASCIMENTO,M. MARASCHIN, N.C. (Org.). Pesquisar na diferença, Um abecedário. Porto Alegre:Sulina, 2012. p. 191-193.

LEMOS, F. C. S: et al.Análise documental: algumas pistas para pesquisar Psicologia e História. Psicologia em Estudo, Maringá, v. 20. n. 3, p. 461-469, jul./set. 2015.

MALATIAN, T. Narrador, registro e arquivo. In: PINSKY ,C. B.; LUCA,T. R. (Org.). 0 historiador e suas fontes. São Paulo: Contexto, 2009. p. 195-222.

MARTÍN-POZUELO CAMPILLOS, María Paz. La construcción teórica en archivística: el principio de procedencia. Madrid: Universidad Carlos III de Madrid: Boletín Oficial del Estado, 1996.

MIRANDA, Antônio; SIMEÃO, Elmira. Uma proposta conceitual para a massa documental considerando o ciclo de interação entre tecnologia e o registro do conhecimento. Biblios, v. 4, n. 15, p. 77-86, 2003.

MIRANDA, Antônio. Comunicação extensiva e animaverbivocovisualidade - av3: formas de expressão na criação artística, literária e científica. eBook Kindle, 2019.

MIRANDA, Antônio. Alfabetização digital e acesso ao conhecimento. Brasília: Universidade de Brasília, Departamento de Ciência da Informação e Documentação, 2006. (Comunicação da informação digital; 4). 
OTLET, Paul. Tratado de Documentación. 2. ed. Murcia: Editum Ediciones de la Universidad de Murcia, 2011.

PAES, Marielena Leite. Arquivo: teoria e prática.3. ed.. Rio de Janeiro: FGV, 2010.

POPPER, Karl Raymond. Conhecimento objetivo: uma abordagem revolucionária. Belo Horizonte: Editora Itatiaia; São Paulo: Universidade de São Paulo, 1975. (Espírito de Nosso Tempo, v.13).

ROUSSEAU, Jean-Yves; COUTURE, Carol. Os fundamentos da disciplina arquivística. Lisboa: Dom Quixote, 1998. 356 p.

VEYNE, P. Como se escreve a história. Brasília: Edições 70, 2008. 